\title{
Detection of two non-synonymous SNPs in SLC45A2 on BTA20 as candidate causal mutations for oculocutaneous albinism in Braunvieh cattle
}

\author{
Sophie Rothammer ${ }^{1}$, Elisabeth Kunz ${ }^{1}$, Doris Seichter ${ }^{2}$, Stefan Krebs $^{3}$, Martina Wassertheurer ${ }^{4}$, Ruedi Fries ${ }^{5}$,
} Gottfried Brem ${ }^{4}$ and Ivica Medugorac ${ }^{1 *}$ (D)

\begin{abstract}
Background: Cases of albinism have been reported in several species including cattle. So far, research has identified many genes that are involved in this eye-catching phenotype. Thus, when two paternal Braunvieh half-sibs with oculocutaneous albinism were detected on a private farm, we were interested in knowing whether their phenotype was caused by an already known gene/mutation.

Results: Analysis of genotyping data (50K) of the two albino individuals, their mothers and five other relatives identified a 47.61-Mb candidate haplotype on Bos taurus chromosome BTA20. Subsequent comparisons of the sequence of this haplotype with sequence data from four Braunvieh sires and the Aurochs genome identified two possible candidate causal mutations at positions 39,829,806 bp (G/A; R45Q) and 39,864,148 bp (C/T; T444I) that were absent in 1682 animals from various bovine breeds included in the 1000 bull genomes project. Both polymorphisms represent coding variants in the SLC45A2 gene, for which the human equivalent harbors numerous variants associated with oculocutaneous albinism type 4. We demonstrate an association of R45Q and T444I with the albino phenotype by targeted genotyping.

Conclusions: Although the candidate gene SLC45A2 is known to be involved in albinism in different species, to date in cattle only mutations in the TYR and MITF genes were reported to be associated with albinism or albinism-like phenotypes. Thus, our study extends the list of genes that are associated with bovine albinism. However, further research and more samples from related animals are needed to elucidate if only one of these two single nucleotide polymorphisms or the combination of both is the actual causal variant.
\end{abstract}

\section{Background}

Many cattle breeds are easily recognized by their characteristic coat color patterns that visually separate them from each other, e.g. Pinzgauer with their chestnut base color and a white dorsal and ventral stripe, the whiteheaded Fleckvieh, or Braunvieh with their eponymous brown color and mealy muzzle. The different colors of

\footnotetext{
*Correspondence: ivica.medjugorac@gen.vetmed.uni-muenchen.de ${ }^{1}$ Chair of Animal Genetics and Husbandry, LMU Munich, Veterinaerstr. 13, 80539 Munich, Germany

Full list of author information is available at the end of the article
}

hair and eyes in mammals are largely determined by the ratio between eumelanin and pheomelanin, the two main types of melanin [1]. Disruptions in melanin biosynthesis result in a lack or complete absence of pigment in the skin, its appendages and the eyes. These phenotypes are summarized under the term "albinism" and can be broadly assigned to two different categories: oculocutaneous or complete albinism (OCA), which is characterized by complete absence of melanin, and ocular albinism, for which the lack of pigment is only restricted to the eyes [2]. Other disorders that lead to completely or partially white skin and hair are summarized under the term "leucism". In 
contrast to albinism, individuals affected by leucism show pigmented irides that can be heterochromatic or vivid blue [3]. Only recently, a study described the case of a single Holstein calf affected by microphthalmia and absence of pigmentation with a phenotype that was most likely caused by an impaired function of the MITF gene, which is known to affect pigmentation in various species [4]. Cases of complete or partial albinism have been reported in several cattle breeds and crossbreeds, e.g. Holstein [5-8], Schwarzbuntes Niederungsrind [9], Hereford [10], Guernsey [11], Beef Shorthorn [12], Charolais [13], Braunvieh/Brune des Alpes [14-16] and Fleckvieh [17]. While, in the past, some breeders who were fascinated by the extraordinary phenotype of albino individuals tried to establish pure white populations [5], nowadays albinism is widely regarded as a deleterious trait since affected animals do not fit their breeds' standards and are more prone to UV damage due to the lack of protective melanin [18]. From a genetic point of view, the mode of inheritance is autosomal recessive in most cases $[7,9,12,14$, 19]. In Hereford [10, 20] and Fleckvieh with partial albinism [17], dominant inheritance was suggested (OMIA 000204-9913). Since melanogenesis involves numerous proteins and biochemical reaction steps, albinism cannot be traced back to a single gene only [21]. Schmutz et al. [16] identified a frameshift mutation in the TYR gene on Bos taurus chromosome (BTA) 29 (OMIA 000202-9913) that causes albinism in Brown Swiss cattle, while a premature stop codon in TYR (OMIA 000202-89462) is responsible for the same condition in water buffalo [19]. Philipp et al. [17] reported a missense mutation in the MITF gene on BTA22 that is accompanied by a white phenotype, heterochromia irides and bilateral hearing loss in German White Fleckvieh.

In this paper, we present a case of oculocutaneous albinism in two related Braunvieh calves that is most probably caused by a mutation in the SLC45A2 gene on BTA20.

\section{Methods}

\section{Animal samples}

Two Braunvieh calves (BV-ALBINO1 and BV-ALBINO2) with oculocutaneous albinism were reported on a private farm. Both animals were fathered by the same sire and displayed a phenotype that was characterized by a complete lack of pigment in the skin, hair, eyes, horns and hooves. The albino phenotype was not present in either of their parents, which were half-sibs. Moreover, besides these two albino calves, the bull had also sired 14 calves with a wild type color pattern. For these reasons, we hypothesized that this trait had a recessive mode of inheritance.

Blood and hair samples from both calves, their dams and eight other relatives were collected on the farm.
Since the bull was used as a natural service sire and had already been slaughtered before the birth of the albino calves, we did not have access to tissue samples of their sire. Samples of the other animals used in this study were either already stored at the LMU Chair of Animal Genetics and Husbandry and originated from previous research projects or were stored at the Tierzuchtforschung e.V. München after paternity control. Table 1 summarizes information on the breeds and numbers of animals included in this study and on the methods applied.

\section{Genotyping}

In this study, samples from both albino calves, their mothers, and one other relative were genotyped, while four related artificial insemination bulls and 85 unrelated animals had already been genotyped in previous studies using the Illumina Bovine SNP50 BeadChip (Illumina, San Diego, USA). Chromosomal positions of all single nucleotide polymorphisms (SNPs) were determined according to release UMD 3.1 of the Bos taurus reference genome [22]. In a subsequent filtering step, we excluded SNPs (1) that were successfully genotyped in less than $95 \%$ of the animals, (2) that frequently showed paternity conflicts in animals with known ancestry, and (3) for which physical positions in the reference genome were unknown or ambiguous. Reconstruction of haplotypes and imputation of missing genotypes were performed

Table 1 List of breeds and number of animals included in the analysis and methods applied

\begin{tabular}{llllll}
\hline Breed or group & Total & KASP $^{\text {TM }}$ & RFLP & Mapping & WGS \\
\hline Albino-Braunvieh & 2 & 2 & 2 & 2 & $1^{\text {b }}$ \\
Albino-Braunvieh relatives $^{\mathrm{a}}$ & 10 & 10 & 10 & 7 & - \\
Braunvieh $^{\text {Original Braunvieh }}$ & 327 & 263 & 281 & 51 & $4^{\mathrm{c}}$ \\
Croatian Busha & 38 & 23 & 24 & 34 & - \\
BV-crossbred & 6 & 6 & 6 & - & - \\
Galloway & 2 & 2 & 2 & - & - \\
Lakenvelder & 10 & 10 & 10 & - & - \\
Diverse breeds (1000 bull & 12 & 12 & 12 & - & - \\
$\quad$ genomes project) & & - & - & - & 1682 \\
Aurochs [26] & - & - & - & - & 1 \\
Total & 407 & 328 & 347 & 94 & 1688 \\
\hline
\end{tabular}

Number of animals per breed group, which were used either for mapping candidate haplotypes and/or genotyping of candidate variants by KASP ${ }^{\mathrm{TM}}$ (T444I) and/or RFLP (R45Q)

The last two columns show the numbers of animals, which were used for the initial haplotype-based mapping procedure and for whole-genome sequencing (WGS) analyses

a Two dams and eight close relatives of the two albino calves sampled on the same farm

b Sequenced in this study

c Sequenced in a previous study [29] and used for variant calling with SAMtools mpileup 
with the program BEAGLE 3.0.4 [23], which operates on a hidden Markov model.

\section{Identification of a common haplotype}

In order to identify a common haplotype associated with the cases of oculocutaneous albinism in this study and, thus, to narrow down the chromosomal intervals that may contain the causative mutation(s), SNP genotypes of the two albino animals, their relatives and a representative sample of the Braunvieh and Original Braunvieh breeds (Table 1) were analyzed using sliding windows with a fixed size of 40 SNPs. Under the assumption of a recessive mode of inheritance, only haplotypes that were homozygous in both albino individuals, heterozygous in their dams, and heterozygous or not present in all other animals were considered for further analyses.

\section{Generation of sequence data and identification of candidate causal mutations}

DNA of the albino animal BV-ALBINO1 was sequenced at the Gene Center of the LMU Munich. A sequencing library was prepared from $1 \mu \mathrm{g}$ of genomic DNA with the 1S kit from Swift Biosciences (Ann Arbor, USA) and sequenced on one lane in 2*100 bp mode on a HiSeq 1500 instrument (Illumina, San Diego, USA). Sequence reads were then aligned to the UMD 3.1 reference sequence using the Burrows-Wheeler Aligner (BWA) [24]. Variant calling was performed with SAMtools mpileup [25] including sequence data from four additional unrelated Brown Swiss animals and the Aurochs genome [26]. The Ensembl variant effect predictor [27] was used to annotate coding variants within the interval 24,179,172$71,793,734$ bp on BTA20 based on Ensembl Release 85 and RefSeq Release 76. The genotypes of candidate causal variants were validated in 1682 animals from various bovine breeds that were available from the fifth run of the 1000 bull genomes project [28] and in an in-house genotype database [29].

\section{Targeted genotyping by PCR-RFLP and KASP ${ }^{\mathrm{TM}}$}

In order to exclude or verify the SNP at position $39,829,806$ bp on BTA20 as a candidate causal mutation, targeted genotyping by PCR-RFLP was carried out on an extended sample set (Table 1) including additional animals and breeds. After amplification of the DNA segment of interest using the primers $5^{\prime}$-GCTCCATGTCAAAT CCACCT- $3^{\prime}$ and $5^{\prime}$-CCCAGCCTACCTAGCCTACC- ${ }^{\prime}$ and digestion with the restriction enzyme $M s p I$, the resulting fragments were separated and visualized by $2 \%$ ethidium bromide-stained agarose gel electrophoresis. For the second SNP at position 39,864,148 bp on BTA20, targeted genotyping was carried out on the same sample set with a specifically designed $\mathrm{KASP}^{\mathrm{TM}}$ assay (LGC, Teddington, UK).

\section{Results}

Results of the pedigree analysis

As shown in Additional file 1: Fig. S1, both albino individuals were produced by half-sib mating. It is also clear that the bull B1, who was the sire of the albinos' sire S1 and thus their grandsire, carried the albino candidate mutations since these were transmitted to at least four of his descendants. We were also able to show that the sire of bull B1 did not carry these mutations. However, since the dam and granddam of $\mathrm{B} 1$ are no longer alive and the grandsire is unknown, it remains unclear if B1 inherited the mutations from his dam or if they occurred spontaneously. Nevertheless, analysis of the pedigree strongly supports a recessive mode of inheritance.

\section{Results of the mapping and genotyping analyses}

Analysis of genotyping data for the two albino calves, their dams, five relatives and 85 unrelated Braunvieh and Original Braunvieh animals resulted in the detection of a 47.61-Mb haplotype between SNP positions $24,179,723$ and $71,793,734$ bp on BTA20 (Fig. 1a), which was exclusively homozygous in both albino individuals, heterozygous in their dams, and heterozygous or absent in any of the other animals. Besides this extended haplotype, five shorter haplotypes also met these criteria (Table 2). Comparisons of the SNP positions with a list of genes (Table 3) that are known to be involved in albinism showed that SLC45A2 (solute carrier family 45 member 2) on BTA20: 39,829,673-39,867,694 bp was located within the borders of the largest stretch of extended homozygosity. Sequence comparisons between animal BV-ALBINO1, four Braunvieh sires and the Aurochs genome led to the detection of two private alleles at positions 39,829,806 bp (G/A; R45Q) and 39,864,148 bp (C/T; T444I). Both of these SNPs (see Additional file 2: Fig. S2 and Additional file 3: Fig. S3), which were not present in 1682 animals from the 1000 bull genomes project, are located within the SLC45A2 gene.

Targeted genotyping by PCR-RFLP and the $\mathrm{KASP}^{\mathrm{TM}}$ assay confirmed both SNPs at positions 39,829,806 and $39,864,148$ bp on BTA20 as candidate causal mutations. Both albino animals were homozygous for the alternative alleles, whereas their dams and four other relatives, which could be traced back to the same ancestor bull, showed heterozygous genotypes. All other animals were homozygous for the respective reference alleles. However, SIFT scores, which were calculated with the Ensembl variant effect predictor [27] (damaging variant when the score is equal to 0.05 or less, tolerated variant when the score is between 0.05 and 1 ), classified the R45Q mutation as damaging (SIFT score 0), whereas the T444I mutation was predicted as tolerable (SIFT score 0.13, Fig. 1b). Furthermore, protein sequence comparisons between Bos 


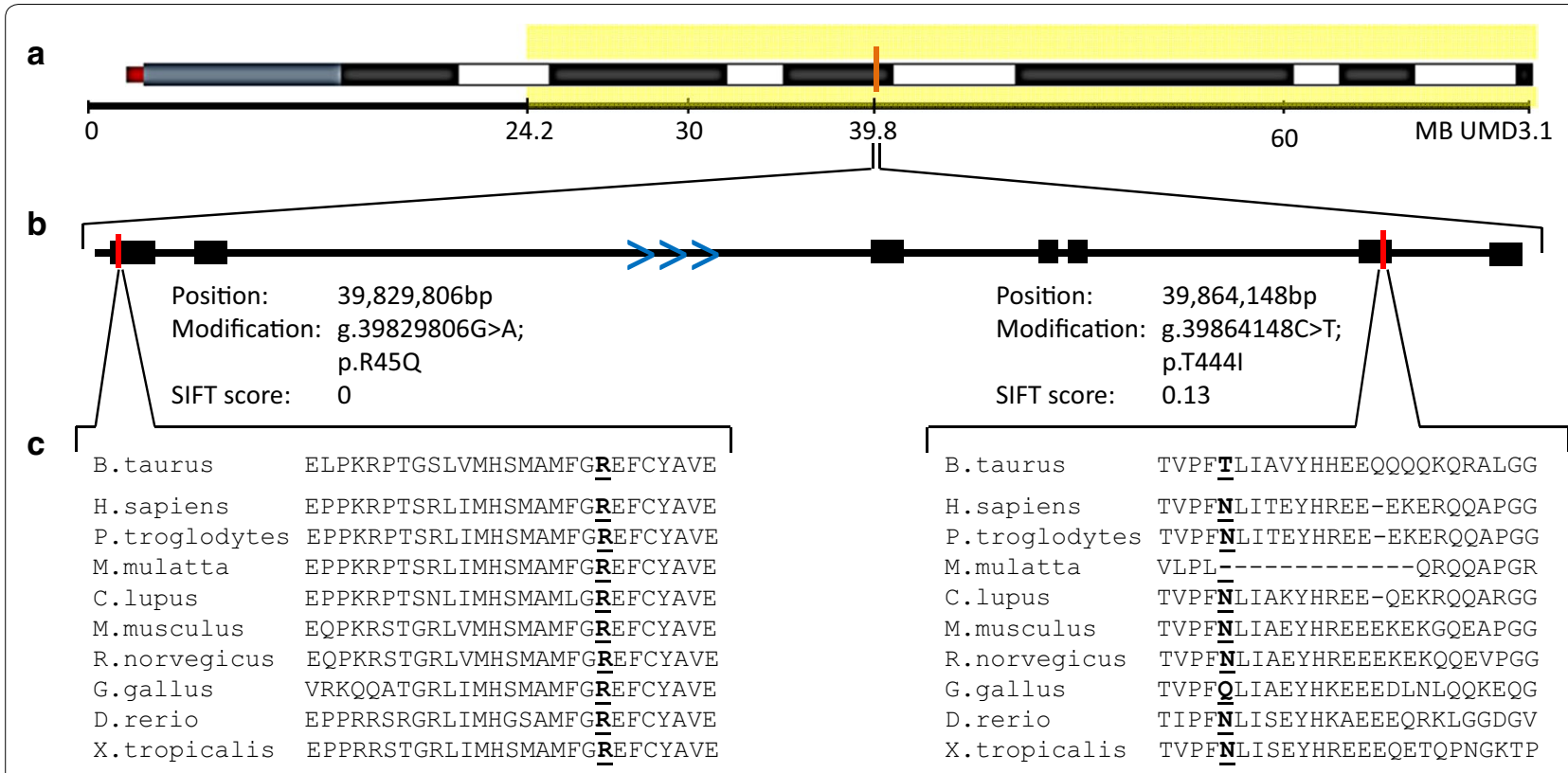

Fig. 1 a Schematic overview of BTA20. Yellow shaded parts mark the candidate haplotype, an orange line indicates the position of SLC45A2 [chromosome adapted to the illustration on CattleQTLdb (http://www.animalgenome.org)]. b Schematic overview of the SLC45A2 gene sequence. Blue arrows indicate the orientation of transcription of SLC45A2. Red lines mark the positions of the two candidate mutations. Exact position according to UMD 3.1, modification and SIFT score are given for each SNP. c Excerpt of the multi-species alignment performed by HomoloGene that clearly shows that p.R45Q is conserved in contrast to p.T444I (indicated in bold face)

\section{Table 2 Candidate haplotypes}

\begin{tabular}{lllrc}
\hline Chr & Start & End & Mb & Number of SNPs \\
\hline 8 & $83,888,935$ & $86,613,020$ & 2.72 & 57 \\
20 & $24,179,723$ & $71,793,734$ & 47.61 & 981 \\
27 & $12,330,184$ & $16,012,903$ & 3.68 & 89 \\
27 & $24,144,679$ & $25,776,811$ & 1.63 & 40 \\
27 & $25,879,452$ & $31,426,001$ & 5.55 & 103 \\
27 & $32,671,451$ & $45,368,987$ & 12.70 & 262 \\
\hline
\end{tabular}

Haplotypes that were homozygous in both albino calves, heterozygous in their dams, and not present in a homozygous state in any of the other animals

taurus and several other species showed that the arginine residue (R45Q) is highly conserved throughout eukaryotes and even more distant species, whereas the threonine residue (T444I) is not (Fig. 1c).

\section{Discussion}

Analysis of sequence data from a Braunvieh animal with oculocutaneous albinism revealed two non-synonymous SNPs in the SLC45A2 gene on BTA20 that were both confirmed as candidate causal mutations by targeted genotyping. Since the mapping procedure was based on simple assumptions (recessive inheritance, mutation not in a common haplotype) and since, in general, the study was based on a candidate gene approach, we could not irrevocably prove that no other equally fitting candidate mutation(s) exist. However, the distribution of the genotypes of g.39829806A $>\mathrm{G}$ and g.39864148C $>\mathrm{T}$ as well as the affected gene SLC45A2 strongly suggest a causal connection between the albino phenotype of the two Braunvieh calves and SLC45A2. Mutations in SLC45A2 (also known as membrane-associated transporter protein, MATP, or antigen isolated from immunoselected melanoma 1, AIM1 [30]) are known to cause a wide range of phenotypes that are characterized by reduced levels or complete absence of melanin synthesis in a variety of species, e.g. white tigers [31], cream-colored horses [32], hypopigmented medaka fish [33], mice with the underwhite (uw) phenotype [34, 35], and chicken and Japanese quail with silver or cinnamon plumage color or imperfect albinism [36]. Furthermore, OCA in a Western lowland gorilla [37], white Doberman pinscher dogs [38] and several long-haired dog breeds [39] was also traced back to mutations in SLC45A2. In zebrafish, Irion et al. [40] demonstrated that repair of a premature stop codon in the SLC45A2 gene using CRISPR/Cas9 led to the production of melanin pigment in the formerly albinotic fish, thus confirming the findings of Dooley et al. [41] who had identified an association between this gene and the albino phenotype. In humans, it has been shown that mutations in SLC45A2 
Table 3 Albinism genes

\begin{tabular}{|c|c|c|}
\hline Type of albinism & Locus & $\begin{array}{l}\text { Position (UMD 3.1, } \\
\text { ENSEMBL) }\end{array}$ \\
\hline $\begin{array}{l}\text { Oculocutaneous albinism } \\
\text { type } 1\end{array}$ & TYR & BTA29: 6,351,877-6,462,240 \\
\hline $\begin{array}{l}\text { Oculocutaneous albinism } \\
\text { type } 2\end{array}$ & OCA2 & $42-598,104$ \\
\hline $\begin{array}{l}\text { Oculocutaneous albinism } \\
\text { type } 3\end{array}$ & TYRP1 & , 698-31,726,956 \\
\hline $\begin{array}{l}\text { Oculocutaneous albinism } \\
\text { type } 4\end{array}$ & SLC45A2 & BTA20: $39,829,673-39,867,694$ \\
\hline $\begin{array}{l}\text { Hermansky-Pudlak Syndrome } \\
\text { type } 1\end{array}$ & HPS1 & BTA26: 19,361,232-19,386,569 \\
\hline $\begin{array}{l}\text { Hermansky-Pudlak Syndrome } \\
\text { type } 2\end{array}$ & $A P 3 B 1$ & BTA10: 9,040,253-9,300,567 \\
\hline $\begin{array}{l}\text { Hermansky-Pudlak Syndrome } \\
\text { type } 3\end{array}$ & HPS3 & $119,944,594-119,985,509$ \\
\hline $\begin{array}{l}\text { Hermansky-Pudlak Syndrome } \\
\text { type } 4\end{array}$ & HPS4 & BTA17: 68,368,661-68,396,020 \\
\hline Chediak-Higashi Syndrome & LYST & BTA28: 8,423,715-8,567,655 \\
\hline Ocular albinism type 1 & GPR143 & BTAX: $143,861,798-143,891,357$ \\
\hline
\end{tabular}

Genes causing albinism according to the albinism database provided by the University of Minnesota (http://www.ifpcs.org/albinism/) and their positions in the cattle genome. The position highlighted in italics was included in one of the candidate haplotypes given in Table 2

are not only the cause of OCA4 [34, 42-47], but that they also play a role in normal skin color variation $[48$, 49].

At the cellular level, Costin et al. [50] suggested that SLC45A2 is involved in the processing and intracellular transport of tyrosinase and other proteins in the melanosome. Due to structural and sequence similarities with plant sucrose transporters, it was also speculated that SLC45A2 might be a transporter for substrates of melanin biosynthesis in the melanosomal membrane [33] or, if it co-transported protons, it might regulate melanosome acidification and thus its function [34]. Dooley et al. [41] showed that SLC45A2 does indeed functions as a $\mathrm{Na}^{+} /$ $\mathrm{H}^{+}$exchanger that is involved in maintaining $\mathrm{pH}$ and ion homeostasis in the melanosome, which in turn influences tyrosinase activity, possibly by copper binding [51]. The transcription of $S L C 4 A 2$ itself is regulated by the transcription factor MITF [35].

In summary, OCA in the two Braunvieh calves analyzed in our study is most possibly caused by a base change in the SLC45A2 gene. However, the question of which of the two non-synonymous SNPs at positions 39,829,806 bp (G/A; R45Q) and 39,864,148 bp (C/T; T444I) is actually the causal mutation, could not be answered yet. Based on the SIFT score results and the fact that a highly conserved arginine residue was identified throughout eukaryotes and more distant species (Fig. 1c), the SNP at position 39,829,806 bp (R45Q) is the most probable causal mutation. Moreover, there also exists the possibility that both mutations are needed to cause the albino phenotype. For example, a similar case of two disease-associated missense mutations that were found on a single haplotype was described for bovine congenital pseudomyotonia [52]. The relatively long common SNP-haplotype (47.61-Mb) that harbored the two candidate mutations, the perfect linkage disequilibrium between both mutations in the investigated samples, and their absence in all Braunvieh animals that were sampled outside of the case herd suggest that both the causal and the hitchhiking mutation were of recent origin, i.e. that they most probably occurred in the case herd recently. Since both mutations are located $34 \mathrm{~kb}$ apart, an independent mutation event is hypothesized. Assuming a genetic distance of $0.034 \mathrm{cM}$ (i.e. $1 \mathrm{Mb}=1 \mathrm{cM}$ ), one recombination per 2941 gametes is expected. Therefore, our chances of sampling an animal that carries only one mutation are very small. An alternative approach would be to produce additional albino animals by mating live heterozygous animals. The albino offspring could then be used for more precise phenotyping. Both BV-ALBINO1 and BV-ALBINO2 showed an unusual muscularity for the Braunvieh breed (Fig. 2). Unfortunately, both calves were slaughtered before we had the opportunity to phenotype them more precisely. The confirmation of this phenotype in additional animals born in independent environments could be of interest for the investigation of a possible pleiotropic effect of one or both mutations. Possible pleiotropy is, at this stage, highly speculative, but we would like to draw the attention to the fact that according to the EMBL-EBI Expression Atlas [53], a low expression of the SLC45A2 gene is observed in bovine muscles, too. Analogous to Irion et al. [40], the effects of both mutations could be tested with the help of the CRISPR/Cas9 methodology [54], if a suitable cell line of a model organism was found.

\section{Conclusions}

Two non-synonymous SNPs at positions 39,829,806 bp (G/A; R45Q) and 39,864,148 bp (C/T; T444I) in the SLC45A2 gene on BTA20 were identified as candidate causal mutations for oculocutaneous albinism in two Braunvieh calves. Thus, SLC45A2 can be added to the list of genes that are responsible for OCA in cattle. To determine which of the two mutations or even if the 

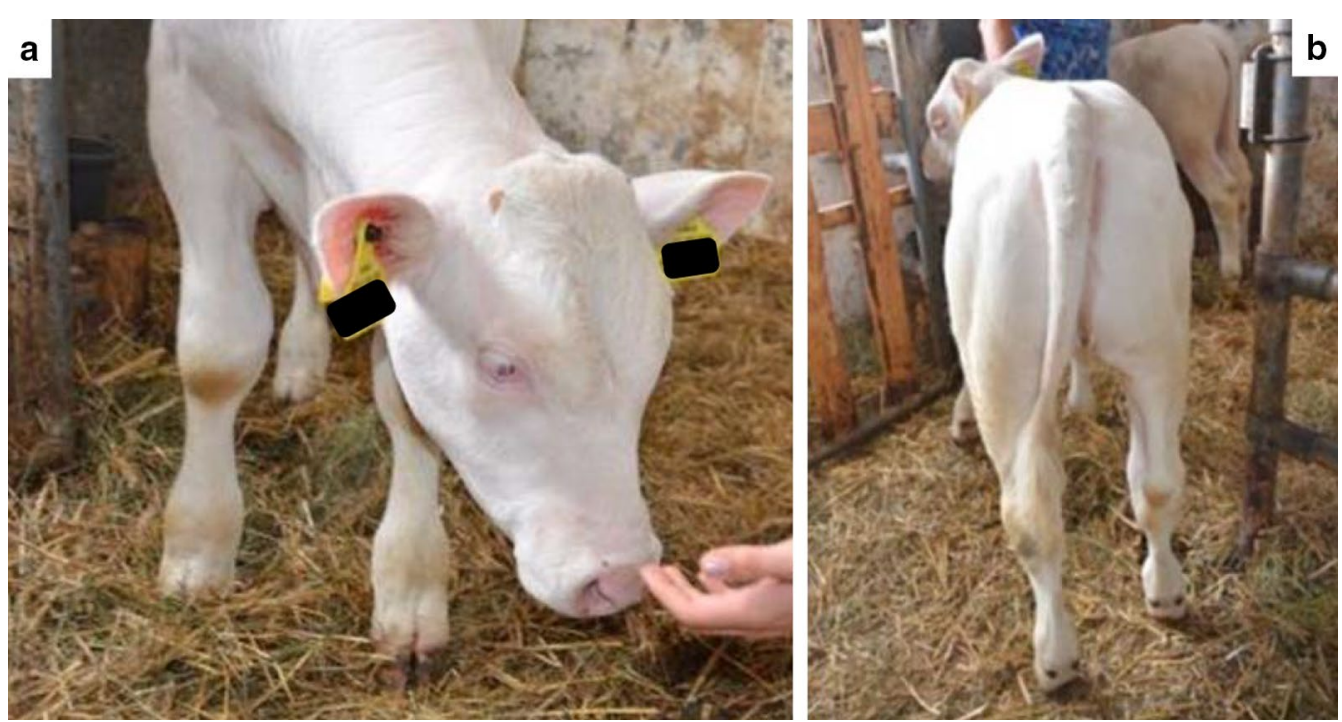

Fig. 2 Pictures of the Braunvieh albino calves. a lllustration of the absence of pigment in the eyes. $\mathbf{b}$ Illustration of the unusual muscling of the calves

combination of both is causal for oculocutaneous albinism in Braunvieh, it would be necessary to produce additional cases and investigate them more precisely.

\section{Additional files}

Additional file 1: Fig. S1. Pedigree of the albino calves. As the red highlighted paths show, both albinos and all carriers of the SNPS g.39829806G>A and g.39864148C>T can be traced back to a single natural service sire (B1). Symbols are as follows: squares = males, circles $=$ females, filled symbols = albinos (homozygous for both SNPs), symbols with dot inside $=$ heterozygous individuals, symbols with question mark inside $=$ genotype unknown, crossed out symbols $=$ no material available. For bull S2, 50K genotype data was available from previous studies; however, no material for targeted genotyping was available.

Additional file 2: Fig. S2. IGV screenshot showing the candidate SNP on BTA20 at position 39,829,806 bp (g.39829806G>A, p.R45Q).

Additional file 3: Fig. S3. IGV screenshot showing the candidate SNP on BTA20 at position 39,864,148 bp (g.39864148C>T, p.T444l).

\section{Authors' contributions}

SR designed and implemented the mapping study, designed targeted genotyping by PCR-RFLP, interpreted data and assisted in drafting the manuscript EK interpreted data and drafted the manuscript. DS performed genotyping, designed and performed targeted genotyping by KASP ${ }^{\mathrm{TM}}$ and critically revised the manuscript. SK performed NGS and critically revised the manuscript. MW performed blood sampling and revised the manuscript. RF filtered and annotated NGS coding variants and performed genotype validation using 1000 bull genomes sequence data and in-house genotype data. GB conceived the study and critically revised the manuscript. IM coordinated the study and critically revised the manuscript. All authors read and approved the final manuscript.

\section{Author details}

${ }^{1}$ Chair of Animal Genetics and Husbandry, LMU Munich, Veterinaerstr. 13, 80539 Munich, Germany. ${ }^{2}$ Tierzuchtforschung e.V. München, Senator-Gerauer-Strasse 23a, 85586 Poing, Germany. ${ }^{3}$ Laboratory for Functional Genome
Analysis, Gene Center, LMU Munich, Feodor-Lynen-Strasse 25, 81377 Munich, Germany. ${ }^{4}$ Institute of Animal Breeding and Genetics, University of Veterinary Medicine Vienna, Veterinaerplatz 1, 1210 Vienna, Austria. ${ }^{5}$ Chair of Animal Breeding, TU Munich, Liesel-Beckmann-Strasse (Hochfeldweg) 1, 85354 Freising-Weihenstephan, Germany.

\section{Acknowledgements}

The authors thank the Braunvieh breeder who provided samples for this study.

\section{Competing interests}

The authors declare that they have no competing interests.

\section{Availability of data and materials}

The 50K genotypes of the albino calves and their relatives that were used and/ or analyzed in the current study are available from the corresponding author on reasonable request. The whole-genome sequencing data of BV-ALBINO1 was uploaded to NCBI and is available under the BioProjectID: PRJNA411962 (http://www.ncbi.nlm.nih.gov/bioproject/411962).

\section{Consent for publication}

Not applicable.

\section{Ethics approval and consent to participate}

Genotypes from previous studies $[55,56]$ as well as additional blood samples collected for DNA extraction were used in this study. Blood sampling was conducted exclusively by certified veterinarians to avoid any unnecessary pain, suffering and/or damage to the animals. Sampling thus complied with the ethical guidelines of the LMU Munich.

\section{Funding}

Not applicable.

\section{Publisher's Note}

Springer Nature remains neutral with regard to jurisdictional claims in published maps and institutional affiliations.

Received: 4 May 2017 Accepted: 27 September 2017

Published online: 05 October 2017 


\section{References}

1. del Marmol V, Beermann F. Tyrosinase and related proteins in mammalian pigmentation. FEBS Lett. 1996;381:165-8.

2. King RA, Summers CG. Albinism. Dermatol Clin. 1988;6:217-28.

3. Fleck K, Erhardt G, Luhken G. From single nucleotide substitutions up to chromosomal deletions: genetic pause of leucism-associated disorders in animals. Berl Munch Tierarztl Wochenschr. 2016;129:269-81.

4. Wiedemar N, Drögemüller C. A 19-Mb de novo deletion on BTA 22 including MITF leads to microphthalmia and the absence of pigmentation in a Holstein calf. Anim Genet. 2014;45:868-70.

5. Detlefsen JA. A herd of albino cattle. J Hered. 1920;11:378-9.

6. Cole LJ, Van Lone EE, Johansson I. Albinotic dilution of color in cattle. J Hered. 1934;25:145-56.

7. Petersen WE, Gilmore LO, Fitch JB, Winters LM. Albinism in cattle. J Hered. 1944;35:135-44.

8. Ojo SA, Leipold HW. Ocular albinism in a herd of Nigerian-Holstein-Friesian cattle. J Anim Breed Genet. 1976;93:252-4.

9. Krallinger HF. Über die Ausspaltung weisser Kälber in einer schlesischen Herde des Schwarzbunten Niederungsviehs. Züchtungskunde. 1937;12:273-6.

10. Leipold HW, Huston K. A herd of glass-eyed albino Hereford cattle. J Hered. 1966:57:179-82.

11. Leipold HW, Huston K, Gelatt KN. Complete albinism in a Guernsey calf. J Hered. 1968;59:218-20.

12. Greene HJ, Leipold HW, Gelatt KM, Huston K. Complete albinism in beef Shorthorn calves. J Hered. 1973;64:189-92.

13. Jayasekera U, Leipold HW. Albinism in US Charolais cattle. Ann Genet Sel Anim. 1981;13:213-8.

14. Carstens P, Mehner A, Prüfer J. Untersuchungsergebnisse über das Aulftreten und Verhalten von Albinos beim Braunvieh. Züchtungskunde. 1934;9:399-411.

15. Weber W, Lauvergne JJ. Trois cas d'albinisme rencontrés en Suisse dans la race Brune des Alpes. Ann Zootech. 1964:13:151-4.

16. Schmutz SM, Berryere TG, Ciobanu DC, Mileham AJ, Schmidtz BH, Fredholm M. A form of albinism in cattle is caused by a tyrosinase frameshift mutation. Mamm Genome. 2004;15:62-7.

17. Philipp U, Lupp B, Mömke S, Stein V, Tipold A, Eule JC, et al. A MITF mutation associated with a dominant white phenotype and bilateral deafness in German Fleckvieh cattle. PLoS One. 2011;6:e28857.

18. Polanowski AM, Robinson-Laverick SM, Paton D, Jarman SN. Variation in the tyrosinase gene associated with a white humpback whale (Megaptera novaeangliae). J Hered. 2012;103:130-3.

19. Damé MCF, Xavier GM, Oliveira-Filho JP, Borges AS, Oliveira HN, Riet-Correa $F$, et al. A nonsense mutation in the tyrosinase gene causes albinism in water buffalo. BMC Genet. 2012;13:62.

20. Leipold HW, Huston K. Incomplete albinism and heterochromia irides in Herefords. J Hered. 1968;59:3-8.

21. Oetting WS, King RA. Molecular basis of albinism: mutations and polymorphisms of pigmentation genes associated with albinism. Hum Mutat. 1999;13:99-115.

22. Zimin AV, Delcher AL, Florea L, Kelley DR, Schatz MC, Puiu D, et al. A whole-genome assembly of the domestic cow, Bos taurus. Genome Biol. 2009;10:R42.

23. Browning BL, Browning SR. A unified approach to genotype imputation and haplotype-phase inference for large data sets of trios and unrelated individuals. Am J Hum Genet. 2009;84:210-23.

24. Li H, Durbin R. Fast and accurate short read alignment with BurrowsWheeler transform. Bioinformatics. 2009;25:1754-60.

25. Li H, Handsaker B, Wysoker A, Fennell T, Ruan J, Homer N, et al. The sequence alignment/map format and SAMtools. Bioinformatics. 2009;25:2078-9.

26. Park SDE, Magee DA, McGettigan PA, Teasdale MD, Edwards CJ, Lohan AJ, et al. Genome sequencing of the extinct Eurasian wild aurochs, Bos primigenius, illuminates the phylogeography and evolution of cattle. Genome Biol. 2015;16:234.

27. McLaren W, Gil L, Hunt SE, Riat HS, Ritchie GR, Thormann A, et al. The Ensembl variant effect predictor. Genome Biol. 2016;17:122

28. Daetwyler HD, Capitan A, Pausch H, Stothard P, van Binsbergen R, Brondum RF, et al. Whole-genome sequencing of 234 bulls facilitates mapping of monogenic and complex traits in cattle. Nat Genet. 2014:46:858-65.
29. Schwarzenbacher H, Burgstaller J, Seefried FR, Wurmser C, Hilbe M, Jung $\mathrm{S}$, et al. A missense mutation in TUBD1 is associated with high juvenile mortality in Braunvieh and Fleckvieh cattle. BMC Genomics. 2016;17:400

30. Suzuki T, Hayashi M. Oculocutaneous albinism type 4. Seattle: University of Washington; 2005.

31. Xu X, Dong GX, Hu XS, Miao L, Zhang XL, Zhang DL, et al. The genetic basis of white tigers. Curr Biol. 2013;23:1031-5.

32. Mariat $\mathrm{D}$, Taourit $\mathrm{S}$, Guerin $\mathrm{G}$. A mutation in the MATP gene causes the cream coat colour in the horse. Genet Sel Evol. 2003;35:119-33.

33. Fukamachi S, Shimada A, Shima A. Mutations in the gene encoding B, a novel transporter protein, reduce melanin content in medaka. Nat Genet. 2001;28:381-5.

34. Newton JM, Cohen-Barak O, Hagiwara N, Gardner JM, Davisson MT, King RA, et al. Mutations in the human orthologue of the mouse underwhite gene (uw) underlie a new form of oculocutaneous albinism, OCA4. Am J Hum Genet. 2001;69:981-8.

35. Du J, Fisher DE. Identification of Aim-1 as the underwhite mouse mutant and its transcriptional regulation by MITF. J Biol Chem. 2002;277:402-6.

36. Gunnarsson U, Hellström AR, Tixier-Boichard M, Minvielle F, Bed'hom B, Ito $S$, et al. Mutations in SLC45A2 cause plumage color variation in chicken and Japanese quail. Genetics. 2007;175:867-77.

37. Prado-Martinez J, Hernando-Herraez I, Lorente-Galdos B, Dabad M, Ramirez O, Baeza-Delgado C, et al. The genome sequencing of an albino Western lowland gorilla reveals inbreeding in the wild. BMC Genomics. 2013;14:363.

38. Winkler PA, Gornik KR, Ramsey DT, Dubielzig RR, Venta PJ, Petersen-Jones SM, et al. A partial gene deletion of SLC45A2 causes oculocutaneous albinism in Doberman Pinscher dogs. PLoS One. 2014;9:e92127.

39. Wijesena HR, Schmutz SM. A missense mutation in SLC45A2 is associated with albinism in several small long haired dog breeds. J Hered. 2015:106:285-8.

40. Irion U, Krauss J, Nüsslein-Volhard C. Precise and efficient genome editing in zebrafish using the CRISPR/Cas9 system. Development. 2014;141:4827-30.

41. Dooley C, Schwarz H, Mueller K, Mongera A, Konantz M, Neuhauss S, et al. Slc45a2 and $\mathrm{V}$-ATPase are regulators of melanosomal $\mathrm{pH}$ homeostasis in zebrafish, providing a mechanism for human pigment evolution and disease. Pigment Cell Melanoma Res. 2013:26:205-17.

42. Rundshagen U, Zühlke C, Opitz S, Schwinger E, Käsmann-Kellner B. Mutations in the MATP gene in five German patients affected by oculocutaneous albinism type 4. Hum Mutat. 2004;23:106-10.

43. Inagaki K, Suzuki T, Ito S, Suzuki N, Adachi K, Okuyama T, et al. Oculocutaneous albinism type 4: six novel mutations in the membrane-associated transporter protein gene and their phenotypes. Pigment Cell Res. 2006;19:451-3.

44. Suzuki T, Inagaki K, Fukai K, Obana A, Lee ST, Tomita Y. A Korean case of oculocutaneous albinism type IV caused by a D157 N mutation in the MATP gene. Br J Dermatol. 2005;152:174-5

45. Li H, Meng S, Zheng H, Wei H, Zhang Y. A Chinese case of oculocutaneous albinism type 4 with two novel mutations. Int J Dermatol. 2008:47:1198-201.

46. Mauri L, Barone L, Al Oum M, Del Longo A, Piozzi E, Manfredini E, et al. SLC45A2 mutation frequency in oculocutaneous albinism Italian patients doesn't differ from other European studies. Gene. 2014;533:398-402.

47. Sengupta M, Chaki M, Arti N, Ray K. SLC45A2 variations in Indian oculocutaneous albinism patients. Mol Vis. 2007;13:1406-11.

48. Lehman AL, Silvers WK, Puri N, Wakamatsu K, Ito S, Brilliant MH. The underwhite (uw) locus acts autonomously and reduces the production of melanin. J Invest Dermatol. 2000;115:601-6.

49. Stokowski RP, Pant PVK, Dadd T, Fereday A, Hinds DA, Jarman C, et al. A genomewide association study of skin pigmentation in a South Asian population. Am J Hum Genet. 2007:81:1119-32.

50. Costin GE, Valencia JC, Vieira WD, Lamoreux ML, Hearing VJ. Tyrosinase processing and intracellular trafficking is disrupted in mouse primary melanocytes carrying the underwhite (uw) mutation. A model for oculocutaneous albinism (OCA) type 4. J Cell Sci. 2003;116:3203-12.

51. Bin BH, Bhin J, Yang SH, Shin M, Nam YJ, Choi DH, et al. Membraneassociated transporter protein (MATP) regulates melanosomal pH and influences tyrosinase activity. PLoS One. 2015;10:e0129273. 
52. Murgiano L, Sacchetto R, Testoni S, Dorotea T, Mascarello F, Liguori R, et al. Pseudomyotonia in Romagnola cattle caused by novel ATP2A1 mutations. BMC Vet Res. 2012;8:186

53. Petryszak R, Keays M, Tang YA, Fonseca NA, Barrera E, Burdett T, et al. Expression Atlas update-an integrated database of gene and protein expression in humans, animals and plants. Nucleic Acids Res. 2016;44:D746-52.

54. Doudna JA, Charpentier E. Genome editing. The new frontier of genome engineering with CRISPR-Cas9. Science. 2014;346:1258096.
55. Kunz E, Rothammer S, Pausch H, Schwarzenbacher H, Seefried FR, Matiasek K, et al. Confirmation of a non-synonymous SNP in PNPLA8 as a candidate causal mutation for Weaver syndrome in Brown Swiss cattle. Genet Sel Evol. 2016:48:21.

56. Medugorac I, Veit-Kensch CE, Ramljak J, Brka M, Markovic B, Stojanovic S, et al. Conservation priorities of genetic diversity in domesticated metapopulations: a study in taurine cattle breeds. Ecol Evol. 2011;1:408-20.

\section{Submit your next manuscript to BioMed Central and we will help you at every step:}

- We accept pre-submission inquiries

- Our selector tool helps you to find the most relevant journal

- We provide round the clock customer support

- Convenient online submission

- Thorough peer review

- Inclusion in PubMed and all major indexing services

- Maximum visibility for your research

Submit your manuscript at www.biomedcentral com/submit 